\title{
Evaluation of single cell oil (SCO) from a tropical marine yeast Yarrowia lipolytica NCIM 3589 as a potential feedstock for biodiesel
}

\author{
Gouri Katre ${ }^{1}$, Chirantan Joshi ${ }^{1,2}$, Mahesh Khot ${ }^{1}$, Smita Zinjarde ${ }^{1}$ and Ameeta RaviKumar ${ }^{1 *}$
}

\begin{abstract}
Single cell oils (SCOs) accumulated by oleaginous yeasts have emerged as potential alternative feedstocks for biodiesel production. As lipid accumulation is species and substrate specific, selection of an appropriate strain is critical. Five strains of Y. lipolytica, a known model oleaginous yeast, were investigated to explore their potential for biodiesel production when grown on glucose and inexpensive wastes. All the strains were found to accumulate $>20 \%(\mathrm{w} / \mathrm{w})$ of their dry cell mass as lipids with neutral lipid as the major fraction when grown on glucose and on wastes such as waste cooking oil (WCO), waste motor oil (WMO). However, amongst them, Y. lipolytica NCIM 3589, a tropical marine yeast, exhibited a maximal lipid/biomass coefficient, $Y_{L / X}$ on $30 \mathrm{~g} \mathrm{~L}^{-1} \mathrm{glucose}$ $\left(0.29 \mathrm{~g} \mathrm{~g}^{-1}\right)$ and on $100 \mathrm{~g} \mathrm{~L}^{-1}$ WCO $\left(0.43 \mathrm{~g} \mathrm{~g}^{-1}\right)$ with a high content of saturated and monounsaturated fatty acids similar to conventional vegetable oils used for biodiesel production. The experimentally determined and predicted biodiesel properties of strain 3589 when grown on glucose and WCO, such as density $\left(0.81\right.$ and $\left.1.04 \mathrm{~g} \mathrm{~cm}^{-3}\right)$, viscosity (4.44 and $3.6 \mathrm{~mm}^{2} \mathrm{~s}^{-1}$ ), SN (190.81 and 256), IV (65.7 and 37.8) and CN (56.6 and 50.8) are reported for the first time for Y. lipolytica and correlate well with specified standards. Thus, the SCO of oleaginous tropical marine yeast Y. lipolytica NCIM 3589 could be used as a potential feedstock for biodiesel production.
\end{abstract}

Keywords: Y. lipolytica, Single cell oil, Fatty acid methyl ester, Biodiesel, WCO

\section{Introduction}

The widespread use of fossil fuels such as petroleum, coal and natural gas, due to the high energy demand in today's industrial world has led to problems of resource scarcity and environmental pollution. Fossil fuels have an additional disadvantage that they are not renewable. Biofuels as alternatives for petroleum fuel have generated great interest in recent years. Amongst them biodiesel from plant, algal and microbial sources seems to hold a partial solution to the ever increasing demand for energy, since their cell or biomass is renewable. General advantages of biodiesel include biodegradability, higher flash point, reduction in exhaust emissions, miscibility in all ratios with petrodiesel, compatibility with the existing fuel distribution infrastructure and inherent lubricity (Knothe 2008).

\footnotetext{
* Correspondence: ameeta@unipune.ac.in

${ }^{1}$ Institute of Bioinformatics and Biotechnology, University of Pune,

Ganeshkhind, Pune 411 007, India

Full list of author information is available at the end of the article
}

The use of microbes as feedstock for biodiesel has advantages such as their short life cycle, requires less labor and lower land resources, are easier to scale up, and are less affected by venue, season or climate ( $\mathrm{Li}$ et al. 2008). Oleaginous microbes (bacteria, fungi and micro algae) are known to accumulate lipids in the form of triacylglycerols (TAGs) (Ratledge and Wynn 2002). The production of microbial lipids or Single Cell Oils (SCOs) has evoked considerable attention during the past decade since these SCOs can be used as a potential feedstock for the production of biodiesel (Meng et al. 2009; Kosa and Ragauskas 2011). Ramos et al. (2009) have shown that the biodiesel quality depends upon the fatty acid composition of the oil feedstock. For an oleaginous microbe to be considered as a suitable feedstock for biodiesel, the total lipid content $(>20 \%)$ and the type of fatty acids (long chain saturated and/or monounsaturated fatty acids) are important criteria. Lipid content and fatty acid composition of SCOs varies in response to environmental factors such as type of carbon 
source, $\mathrm{pH}$, temperature and is species and strainspecific (Subramaniam et al. 2010; Venkata Subhash and Venkata Mohan 2011). This is evident from the studies on the psychrophilic oleaginous yeast Rhodotorula glacialis wherein both glucose concentration and temperature influenced the composition and degree of unsaturation of fatty acids (Amaretti et al. 2010). It has also been reported that the energy capacity of the dry yeast cell mass depends on the total lipid content, wherein $64 \%$ of the lipid content corresponded to $73 \%$ of the energy value of dry biomass (Minkevich et al. 2010). Consequently, since the accumulation of lipids by oleaginous yeasts varies, not all oleaginous yeasts can be used as a feedstock for biodiesel production. Therefore, careful selection of the oleaginous strains of the microbial species and characterization of lipid composition need to be performed to ascertain their suitability for biodiesel production.

Among the oleaginous yeasts, Yarrowia lipolytica, an unconventional microbe, has been extensively studied and is often isolated from lipid and hydrocarbon rich habitats, such as dairy products, polluted effluents and raw poultry. The potential biotechnological applications of $Y$. lipolytica using various environmental and industrial wastes have been discussed (Bankar et al. 2009). This yeast is known to degrade alkanes, fatty acids, fats and oil and is also a known model organism for lipid accumulation (Beopoulos et al. 2009; Fickers et al. 2005). Moreover, the unique ability of this yeast to efficiently use hydrophobic substrates makes this microorganism a prime candidate for use in the production of bio-oils (Beopoulos et al. 2009). Its hydrophobic substrate utilization and its metabolism directed towards lipid or SCO accumulation has been excellently reviewed by Fickers et al. (2005). Several technologies have been tried for SCO production by $Y$. lipolytica grown on various agro-industrial by-products or wastes and reasonably good cell growth and SCO production has been reported to occur on technical grade glycerol, animal fats, tallow, olive oil mill waste etc. with the major factions being saturated fatty acids (Papanikolaou and Aggelis 2010; Sarris et al. 2011). However, most of these studies have been directed towards production and utilization of these SCOs for various high value-added fats like cocoa butter, or using genetically modified strains for polyunsaturated fatty acids (PUFAs) having medical significance (Papanikolaou and Aggelis 2011). But, to date, hardly any reports from $Y$. lipolytica exist on either the use of SCO as feedstock for biodiesel or their physico-chemical characterization.

The present study investigates the biomass production and lipid accumulation potential of five different wild-type strains of $Y$. lipolytica grown on glucose. Further, utilization of some agro-industrial and other wastes for lipid accumulation by the selected strains were also studied. Lipid accumulation and the fatty acid composition in $Y$. lipolytica is known to depend on the substrate on which the cells are cultivated. These yeasts accumulate high levels of lipids when carbon is in excess and a key nutrient such as nitrogen or phosphorous is limiting (Ratledge and Wynn 2002). The accumulated lipids or SCOs get deposited as intracellular lipid bodies (LBs) which can easily be detected by the fluorescent probe, Nile red (Kimura et al. 2004). The cell mass of these yeast strains was evaluated for lipid content and their transesterified SCO profiles for biodiesel production as the type of fatty acids present are substrate dependent and important in ascertaining its appropriateness for biodiesel. Some physico-chemical properties of the biodiesel from the selected strain(s) were determined and compared with known international norms in order to ascertain its potential suitability as a fuel.

\section{Materials and methods Materials}

Chloroform, methanol, acetone, formaldehyde, $\mathrm{KH}_{2} \mathrm{PO}_{4}$, $\mathrm{Na}_{2} \mathrm{HPO}_{4} \cdot 12 \mathrm{H}_{2} \mathrm{O}$, anhydrous $\mathrm{Na}_{2} \mathrm{SO}_{4}, \mathrm{NaCl}, \mathrm{KCl}$, and $\mathrm{MgCl}_{2}$ were of analytical grade and were purchased from Merck Ltd., Mumbai, India. 1,1,1-trichloroethane was obtained from National Chemicals, Vadodara, India. Potassium iodide and phenolphthalein were obtained from Fisher Scientific, Mumbai, India. Silicic acid, chromatography grade and Nile red were purchased from SigmaAldrich, Inc., USA. 'Bead beater' (Biospec Products, Inc., USA) was used for lysis of yeast cells and Kittiwake DIGI Biodiesel test kit (Kittiwake Developments Ltd., UK) was used for determination of Total Acid Number (TAN) and Free Fatty Acid (FFA) content. Iodine solution (Wijs) was purchased from Acros Organics, Belgium while alcoholic $\mathrm{KOH}$ solution was procured from Merck, Germany.

\section{Strains and growth conditions}

Five strains of $Y$. lipolytica were obtained from The National Collection of Industrial Microorganisms (NCIM), National Chemical Laboratory, Pune, India. These were Y. lipolytica NCIM 3229 (NCYC 153), NCIM 3450, NCIM 3472 (ATCC 8661 and NCYC 825), NCIM 3589 and NCIM 3590 (NCYC 789 and MTCC 35), respectively. All strains were maintained on MGYP medium ( $\mathrm{g} \mathrm{L}^{-1}$ ), 3.0 malt extract; 3.0 yeast extract; 5.0 peptone and 10.0 dextrose, at $4^{\circ} \mathrm{C}$. The medium used for cultivation of biomass was lipid accumulation medium (LAM), containing excess of carbon and limited in nitrogen, according to Suutari et al. (1993) and contained $\left(\mathrm{g} \mathrm{L}^{-1}\right)$, 30.0 glucose, 1.5 yeast extract, $0.5 \mathrm{NH}_{4} \mathrm{Cl}, 5.0 \quad \mathrm{Na}_{2} \mathrm{H}$ -

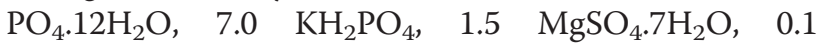
$\mathrm{CaCl}_{2} .2 \mathrm{H}_{2} \mathrm{O}, 0.01 \mathrm{ZnSO}_{4} .7 \mathrm{H}_{2} \mathrm{O}, 0.08 \mathrm{FeCl}_{3} .6 \mathrm{H}_{2} \mathrm{O}$ and $\left(\mathrm{mg} \mathrm{L}^{-1}\right) \quad 0.1 \mathrm{CuSO}_{4} .5 \mathrm{H}_{2} \mathrm{O}, 0.1 \mathrm{Co}\left[\mathrm{NO}_{3}\right]_{2} \cdot 6 \mathrm{H}_{2} \mathrm{O}, 0.1$ $\mathrm{MnSO}_{4} .5 \mathrm{H}_{2} \mathrm{O}$ and $\mathrm{pH}$ adjusted to 5.5 . An initial pre- 
inoculum of cells grown for $48 \mathrm{~h}$ in the abovementioned medium was used. The cells were washed with distilled water and count adjusted to $10^{9}-10^{10}$ cells. These cells were inoculated in $100 \mathrm{ml}$ of above mentioned media and incubated on a rotary incubator shaker $(120 \mathrm{rpm})$ for 24, 48, 72 and $96 \mathrm{~h}$ at $30^{\circ} \mathrm{C}$ for all the four strains except Y. lipolytica NCIM 3590 , which was grown at $20^{\circ} \mathrm{C}$. For each sample, the experiments were carried out in triplicates.

\section{Nile red fluorescence}

The fluorescent dye, Nile red was used to determine lipid accumulation ability of the five strains (Beopoulos et al. 2008; Mlickova et al. 2004). Cells were observed microscopically with an oil immersion objective using a Zeiss microscope (Axio Scope A1), equipped with a digital camera and a 465-495 nm excitation filter. ProgRes CapturePro 2.7 software (Jenoptik optical systems, USA) was used for recording the images.

\section{Extraction of yeast total lipids as SCO}

The harvested cells were washed and lyophilized. This lyophilized dry biomass was weighed and used for extraction of total lipid using bead beater. The cells were added to the $20 \mathrm{ml}$ chamber of the bead beater along with acidwashed glass beads $(0.5 \mathrm{~mm})$ to fill $3 / 4^{\text {th }}$ of the volume. Methanol $(15 \mathrm{ml})$ was added to fill the chamber and a total of $10-12$ cycles of $3 \mathrm{~min}$ each were run at $4^{\circ} \mathrm{C}$ to disrupt cells which was confirmed microscopically. Total lipids were extracted in chloroform: methanol $(2: 1, \mathrm{v} / \mathrm{v})$ according to Schneiter and Daum (2006), the solvent vaccum evaporated and the residual lipid estimated gravimetrically.

\section{Lipid fractionation}

The total yeast lipid (approximately $100 \mathrm{mg}$ ) was dissolved in $1 \mathrm{ml}$ of chloroform: methanol $(2: 1, \mathrm{v} / \mathrm{v})$ and loaded on a $25 \mathrm{~mm} \times 100 \mathrm{~mm}$ silicic acid column $(1 \mathrm{~g}$ silicic acid, activated by heating overnight at $110^{\circ} \mathrm{C}$ ). The lipid was eluted from the column by sequential elution with $100 \mathrm{ml}$ each of 1, 1, 1-trichloroethane, acetone, and methanol and the fractions collected. The solvent from each fraction was evaporated and the weight of the residual lipid determined. The fractions, in order of elution, were neutral lipids, glycolipids plus sphingolipids and phospholipids, respectively. The collected fractions were spotted on a silica gel $F_{254}$ plate and developed according to Latge and De Bievre (1980). Appropriate authentic standards viz., tristearin, phosphatidylcholine and sphingomyelin were chromatographed on each plate. Experimental lipids were identified by comparing their $R f$ values with those of the standards. The fractions showing presence of neutral lipid were pooled to give total neutral lipid of the strain which was estimated gravimetrically.

\section{Transesterification of SCO and analysis of FAMEs}

The SCO obtained was transesterified according to Leung et al. (2010). The reaction was carried out in a $50 \mathrm{ml}$ round bottom flask kept in a thermostatic bath with a reflux condenser and a magnetic stirrer using a methanol to oil molar ratio of $60: 1$ and a catalyst $(\mathrm{NaOH})$ concentration of $1.5-3$ wt. \% relative to SCO. The individual FAMEs in transesterified SCO (biodiesel) were detected using gas chromatography (GC) using CP-Sil88 column (50 m length, $0.25 \mu \mathrm{m}$ ID) and Flame Ionization Detector (FID) as per the AOAC method (AOAC 2005). The resulting profile and retention times were compared with the standard (37 component FAME mix, Supelco, USA) and composition of the individual fatty acid methyl ester determined.

\section{Growth and SCO (total lipid) production of $Y$. lipolytica NCIM 3589 on varying initial glucose concentrations}

The growth and total lipid production of the selected strain was checked on glucose concentration ranging from $10-100 \mathrm{~g} \mathrm{~L}^{-1}$ up to $96 \mathrm{~h}$ at $120 \mathrm{rpm}$ at $30^{\circ} \mathrm{C}$. All other conditions were the same as mentioned earlier. The residual glucose in the media was estimated using 3, 5-dinitrosalicylic acid (DNSA) according to Miller (1959).

\section{Preliminary screening of different wastes as substrates for SCO}

Cheap and locally available substrates such as cheese whey $(50 \%, v / v)$ and agro-residues such as groundnut shell, sugarcane bagasse, grape stalk, groundnut oil cake, copra meal, fruit and vegetable wastes like fruit peel (orange and banana), orange pulp and peapod were washed, dried, ground and passed through sieve of mesh size $1 \mathrm{~mm}$ and added as sole carbon and energy source $(1 \% \mathrm{w} / \mathrm{v})$ to the LAM medium. Fish and chicken wastes were autoclaved for $30 \mathrm{mins}$ and added as minces $(1 \% \mathrm{w} / \mathrm{v})$ to the LAM medium. Prawn shell waste was de-mineralized by treatment with $1 \mathrm{~N} \mathrm{HCl}$ $(1: 15 \mathrm{w} / \mathrm{v})$ and de-proteinized by treatment with $3 \%$ $\mathrm{NaOH}(1: 10 \mathrm{w} / \mathrm{v})$, the residue washed, dried and added at $1 \%(\mathrm{w} / \mathrm{v})$ in the LAM medium. Waste motor oil (WMO) and waste cooking oil (WCO) were also added as $1 \%(\mathrm{v} / \mathrm{v})$ to the medium as described above. The biomass grown on WCO and WMO was made oil-free as per the protocol of Papanikolaou et al. (2010).

A pre-inoculum of the yeast cells was prepared as mentioned above and a cell count of $10^{9}-10^{10}$ cells/ $50 \mathrm{ml}$ was used to inoculate each flask. The flasks were incubated in a rotary incubator shaker $(120 \mathrm{rpm})$ for $72 \mathrm{~h}$ at $30^{\circ} \mathrm{C}$ for all strains except 3590 , which was incubated at $20^{\circ} \mathrm{C}$. 


\section{Growth and SCO (total lipid) production of $Y$. lipolytica NCIM 3589 and Y. lipolytica NCIM 3472 on varying concentrations of WCO}

The growth and total lipid production of the selected strains was checked on WCO concentrations ranging from $10-100 \mathrm{~g} \mathrm{~L}^{-1}$ at $72 \mathrm{~h}\left(120 \mathrm{rpm}, 30^{\circ} \mathrm{C}\right)$. The cells were made fat-free (Papanikolaou et al. 2010), the SCO extracted, transesterified and FAMEs were detected as mentioned earlier.

\section{Physico-chemical characterization of biodiesel properties of $Y$. lipolytica NCIM 3589 on glucose and WCO and Y. lipolytica NCIM 3472 on WCO}

The physico-chemical properties of the biodiesel (FAME) from the strains selected by screening on glucose (NCIM 3589) and on WCO (NCIM 3589 and 3472) were evaluated. Density, kinematic viscosity, saponification number $(\mathrm{SN})$, iodine value (IV) were determined experimentally as well as by using predictive models and mathematical equations for the transesterified SCOs. Density was determined gravimetrically at $25^{\circ} \mathrm{C}$ using a Pycnometer $(10 \mathrm{ml})$. It was also predicted as per Kay's mixing rule (Pratas et al. 2011) as follows:

$$
\rho=\sum c_{i} \rho_{i}
$$

(where $c_{i}$ and $\rho_{i}$ denote concentration and density of individual component $i$, respectively). These values were obtained using the density of individual, pure FAME compounds from the database (Lapuerta et al. 2010).

The values for kinematic viscosity $\left(40^{\circ} \mathrm{C} ; \mathrm{mm}^{2} \mathrm{~s}^{-1}\right)$ were calculated by using the modified equation of Grunberg-Nissan as follows:

$$
v_{\text {mix }}=\sum A_{c} \times v_{c}
$$

in which $v_{\text {mix }}=$ the kinematic viscosity of the biodiesel sample (mixture of fatty acid alkyl esters), $\mathrm{A}_{\mathrm{C}}=$ the relative amount $(\% / 100)$ of the individual neat ester in the mixture (as determined by gas chromatography) and $v_{C}=$ the kinematic viscosity of the individual esters from database of FAMEs present in biodiesel (Knothe and Steidley 2011).

SN and IV were determined experimentally (AOAC 1975) and also calculated using the equations (3) and (4) as follows:

$$
\begin{aligned}
& S N=\sum \frac{\left(560 \times A_{i}\right)}{M W_{i}} \\
& I V=\sum \frac{\left(254 \times D \times A_{i}\right)}{M W_{i}}
\end{aligned}
$$

where, $A_{i}$ is the percentage, $D$ is the number of double bonds and $M W_{i}$ is the molecular mass of each fatty acid methyl ester (Azam et al. 2005; Gunstone et al. 2007)
Another fuel property, Higher Heating Value (HHV), a measure of the heat content of the oil was found to depend upon SN and IV values and was estimated using equation (5) (Demirbas 1998).

$$
H H V=49.43-[0.04(S N)+0.015(I V)]
$$

Cetane Number $(\mathrm{CN})$ was calculated using the multiple linear regression equation. (6) (Tong et al. 2011)

$$
C N=1.068 \sum\left(C N_{i} W_{i}\right)-6.747
$$

where, $\mathrm{CN}_{\mathrm{i}}$ represent reported $\mathrm{CN}$ of pure fatty acid methyl ester available in database (Tong et al. 2011) and $\mathrm{W}_{\mathrm{i}}$ is the mass fraction of individual fatty ester component detected and quantified by GC-FID.

Water content of the sample, TAN and FFA were determined using the Kittiwake DIGI Biodiesel test kit while the copper strip corrosion test was carried out according to ASTM D130 test specifications.

\section{Statistical analysis}

All values are means of three independent experiments. Statistical analyses were performed using SPSS 17 statistics software (SPSS Inc., Chicago, IL, USA). Means were compared and analyzed using either $t$-test or one-way analysis of variance (ANOVA) with Tukey HSD post hoc multiple comparison test. Differences were considered statistically significant for $\mathrm{p}<0.05$.

\section{Results}

Growth and SCO yields of $Y$. lipolytica strains on glucose Lipid accumulation in oleaginous yeasts occurs as LBs when a nutrient in the medium e.g., nitrogen or phosphorous is limiting and carbon is in excess. The lipid yields, fatty acid composition and degree of unsaturation are affected depending on the type and concentration of carbon source (Granger et al. 1993; Ratledge and Wynn 2002; Amaretti et al. 2010). Therefore, we first investigated the effect of glucose, on cell growth, lipid yields and sugar consumption by different $Y$. lipolytica strains.

\section{Determination of lipid accumulation by Nile red staining}

In the present study, all five strains of $Y$. lipolytica when grown in $30 \mathrm{~g} \mathrm{~L}^{-1}$ glucose revealed a variable number of LBs which could be visualized by light microscopy of formaldehyde fixed cells or by fluorescence microscopy of cells stained with Nile red (Figure 1 insets). Variation in number and size of the LBs could be seen in all the strains grown in glucose. Therefore, all the five lipid accumulating strains viz., NCIM 3229, NCIM 3450, NCIM 3472, NCIM 3589, and NCIM 3590 were further assessed for their total cellular lipid (SCO) content. 


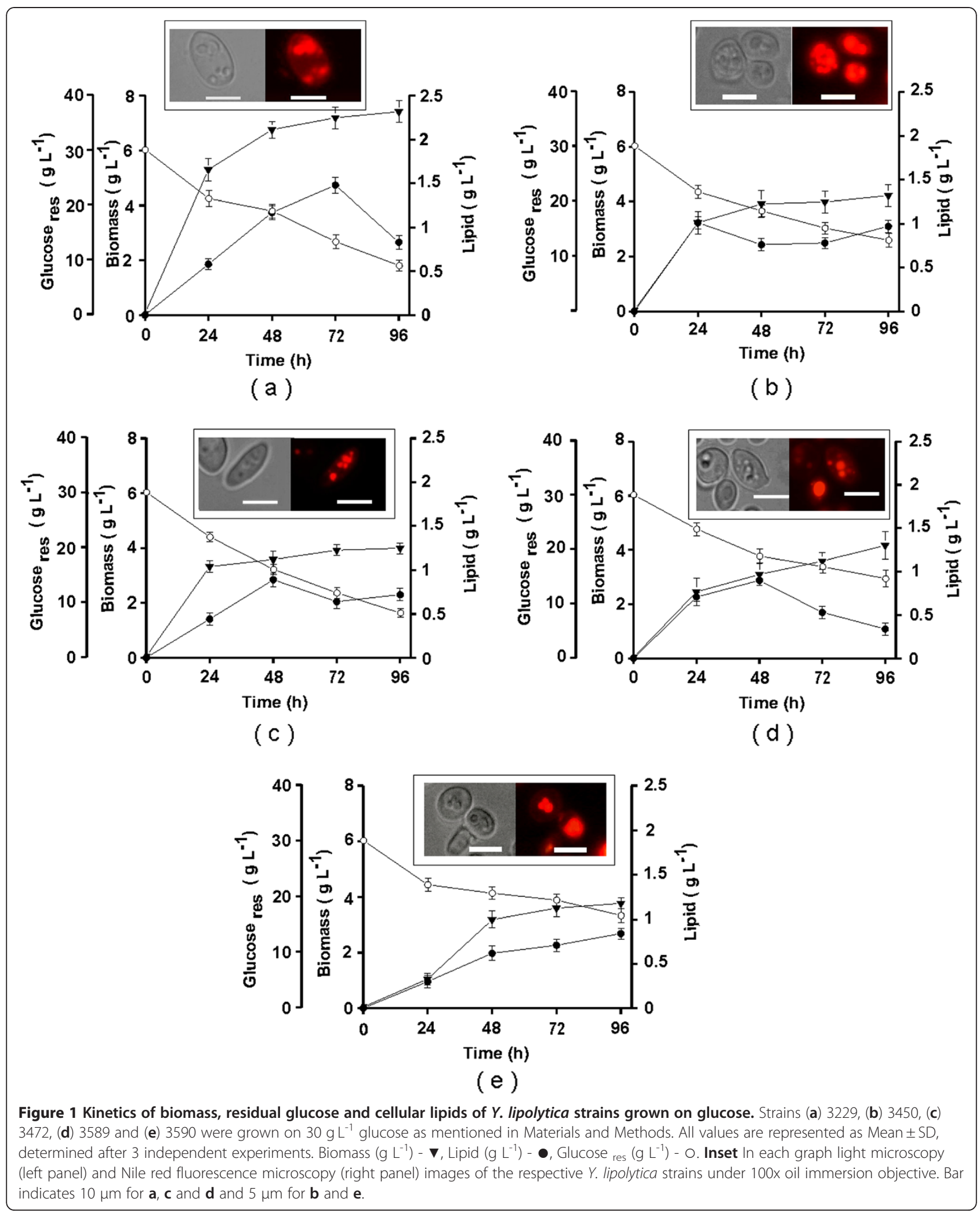

Time course for biomass production and total SCO yields Figure 1 depicts the time course of biomass produced $\left(\mathrm{X}, \mathrm{g} \mathrm{L} \mathrm{L}^{-1}\right)$, lipid yield $\left(\mathrm{L}, \mathrm{g} \mathrm{L}^{-1}\right)$ and residual glucose concentrations (Glucose res, $\mathrm{g} \mathrm{L}^{-1}$ ) against fermentation time in lipid accumulation medium containing $30 \mathrm{~g} \mathrm{~L}^{-1}$ glucose. Under these conditions, all the 5 strains showed 
an increase in biomass which varied from 3.77-7.42 $\mathrm{g} \mathrm{L}^{-1}$ while the maximal lipid yield $\left(\mathrm{L}_{\max }, \mathrm{g} \mathrm{L}^{-1}\right)$ varied from 0.84-1.48 $\mathrm{g} \mathrm{L}^{-1}$ and were achieved in 24-96 h after incubation. The lipid/dry biomass yield coefficient $\left(\mathrm{Y}_{\mathrm{L} / \mathrm{X}}, \mathrm{g} g\right.$ ${ }^{-1}$ ) determined were $0.22 \mathrm{gg}^{-1}$ in $96 \mathrm{~h}$ for strain 3229 (Figure 1a), 0.31 and $0.28 \mathrm{~g} \mathrm{~g}^{-1}$ in $24 \mathrm{~h}$ for strains 3450 and 3590 (Figure $1 \mathrm{~b}, \mathrm{e}$ ), 0.25 and $0.29 \mathrm{gg}^{-1}$ in $48 \mathrm{~h}$ for strains 3472 and 3589 (Figure 1c, d), respectively. Both, $\mathrm{L}_{\max }$ and $\mathrm{Y}_{\mathrm{L} / \mathrm{X}}$ were found to decrease on prolonged incubation and were strain dependent. In all the strains under study, significant amounts of glucose (8.0$16.5 \mathrm{~g} \mathrm{~L}^{-1}$ ) remained unconsumed in the media even after $96 \mathrm{~h}$ of incubation. Thus, all the strains showed a tendency to degrade their storage lipids even though significant amounts of residual glucose remained in the medium. The total lipid content varied from $22-31 \%$ of the total dry weight of biomass and ascertained the oleaginous nature ( $>20 \%$ lipid of the cellular weight) of all the five strains of $Y$. lipolytica tested.

\section{Lipid fractionation}

The extracted SCOs from the five yeast strains grown on glucose were fractionated by silicic acid column chromatography to determine the individual lipid fractions. In all cases, regardless of the quantity of lipid accumulated inside the yeast, the neutral lipid fraction was the most abundant, whereas glycolipid plus sphingolipid and phosopholipid fractions were found in noticeably lower quantities $(<10 \%)$. The neutral lipid fraction includes triacylglycerols (TAGs), one of the key components desirable for biodiesel and the neutral lipid contents of all the strains were found to lie between $88-89 \%$ of the total lipid or SCO content (Figure 2). Thus, the cell mass of all 5 strains contained a high content of SCO with neutral lipid as the major fraction which is the desirable lipid type for biodiesel

\section{Fatty acid profiles of transesterified SCOs}

The SCOs obtained from the yeast strains were subjected to alkali catalyzed trans-esterification to give fatty acid methyl esters (FAME) or biodiesel. The resulting FAME profile and retention times of each methyl ester were compared with the authentic standard (37 component FAME mix, Supelco, USA) by GC-FID, the composition of FAME determined and profiles evaluated for their biodiesel suitability (Table 1).

The content of total saturated fatty acid (SFA) was highest in 3229 (70.6\%) followed by 3590 (64.1\%), 3589 (34.6\%), 3472 (17.1\%) and 3450 (4.9\%) when grown on glucose. Of the total SFAs, strains 3229 and 3450 contained $58.1 \%$ and $4.9 \%$ of odd-chain fatty acid - C13:0 while strains 3590 and 3229 showed $34 \%$ and $12.5 \%$ of C15:0. Palmitic acid (C16:0) was highest in strain 3589 (24.1\%) while stearic acid (C18:0) was present at $7.7 \%$

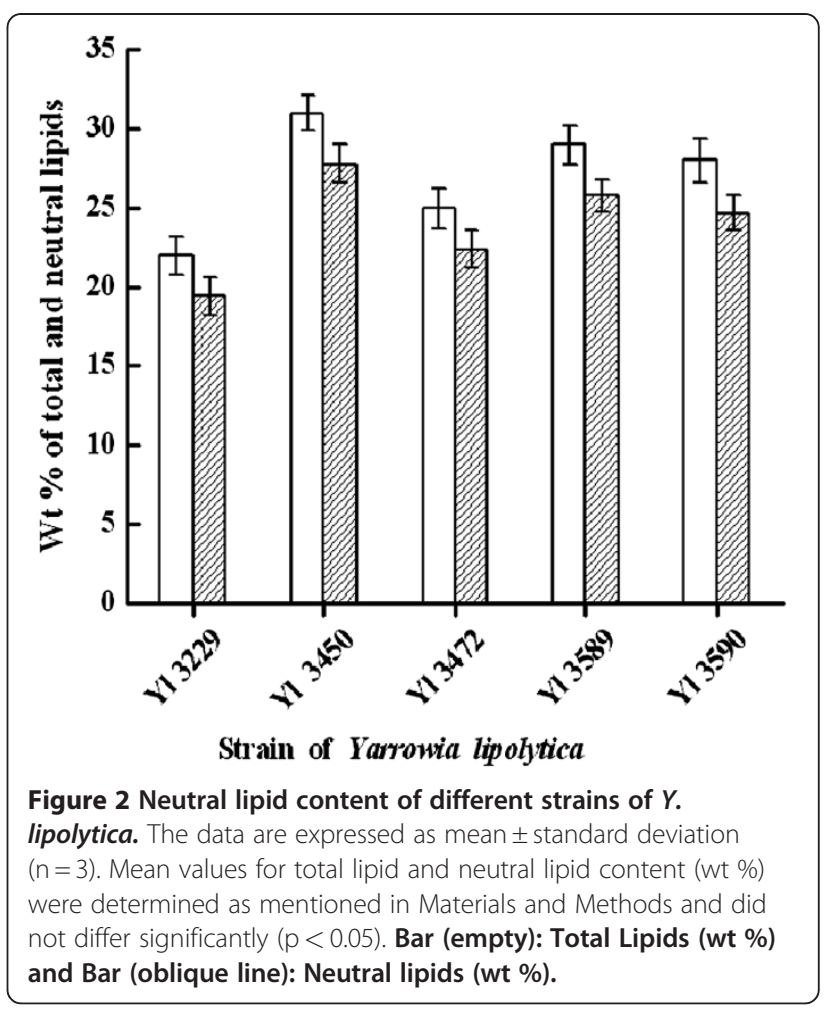

and $4.6 \%$ in 3589 and 3590. Strain 3472 contained $4.8 \%$ arachidic acid (C20:0) and behenic acid C22:0 (12.3\%) while $7.4 \%$ of eicosanoic (C21:0) was present in 3590 . Thus, only the strains 3589 and 3590 contained good amounts C16:0 and C18:0 SFAs required for biodiesel.

The total content of monounsaturated fatty acids, (MUFA) the desirable fatty acids for biodiesel was the highest in 3589 (50.1\%). Lesser amounts were present in $3450(22.8 \%)$ and 3590 (14.3\%) while negligible amounts were present in 3472 and 3229. Palmitoleic acid (C16:1) and oleic acid (C18:1) were highest in 3589 (11\% and $38.6 \%$, respectively). Strain 3450 contained $13.5 \%$ cis-10pentadecanoic acid (C15:1) while erucic acid, C22:1 (9.2\%) was present in 3590 and cis-10-heptadecanoic acid (C17:1) was present at $9.3 \%$ in 3450 . Thus, the long chain MUFAs, C16:1 and C18:1, required for good quality biodiesel were present in high amounts only in strain 3589.

The total polyunsaturated fatty acids (PUFAs) were highest in $3472(82.4 \%)$ followed by 3450 (72.4\%) 3229 (28.8\%), 3590 (21.6\%) and the least in 3589 (15.1\%). PUFAs containing $\geq 4$ double bonds are not desirable for biodiesel (1\% max, according to EN 14214). PUFAs like arachidonic acid (C20:4), eicosapentanoic acid (C20:5) and docosahexanoic acid (C22:6) were present in higher amounts in all four strains except 3589 (19.6\% in $3229,45.3 \%$ in $3450,58.5 \%$ in $3472,0.2 \%$ in 3589 and $18.9 \%$ in 3590 , respectively) making the SCOs of these strains (except strain 3589) unsuitable for biodiesel. 
Table 1 Fatty acid methyl ester profiles of $Y$. lipolytica strains on glucose

\begin{tabular}{|c|c|c|c|c|c|}
\hline$\%$ of fatty acid methyl ester & NCIM 3229 & NCIM 3450 & NCIM 3472 & NCIM 3589 & NCIM 3590 \\
\hline Caprylic acid (C8:0) & ND & ND & ND & ND & 0.4 \\
\hline Lauric acid (C12:0) & ND & ND & ND & ND & 4.8 \\
\hline Tridecanoic acid (C13:0) & 58.1 & 4.9 & ND & ND & ND \\
\hline Myristic acid (C14:0) & ND & ND & ND & 0.4 & 3.9 \\
\hline Pentadecanoic acid (C15:0) & 12.5 & ND & ND & 0.1 & 34.4 \\
\hline Palmitic acid (C16:0) & ND & ND & ND & 24.1 & 2.8 \\
\hline Heptadecanoic acid (C17:0) & ND & ND & ND & ND & 0.4 \\
\hline Stearic acid (C18:0) & ND & ND & ND & 7.7 & 4.6 \\
\hline Arachidic acid (C20:0) & ND & ND & 4.8 & 0.4 & ND \\
\hline Heneicosanoic acid (C21:0) & ND & ND & ND & ND & 7.4 \\
\hline Behenic acid (C22:0) & ND & ND & 12.3 & 0.4 & ND \\
\hline Lignoceric acid (C24:0) & ND & ND & ND & 1.5 & ND \\
\hline Palmitoleic acid C16:1) & ND & ND & ND & 11 & 1.6 \\
\hline Oleic acid (C18:1n9c) & ND & ND & ND & 38.6 & 3.5 \\
\hline cis-10-pentadecanoic acid (C15:1) & ND & 13.5 & ND & ND & ND \\
\hline cis-11Eicosanoic acid (C20:1) & ND & ND & ND & 0.1 & ND \\
\hline Erucic acid (C22:1n9) & ND & ND & ND & ND & 9.2 \\
\hline cis-10-Heptadecanoic acid (C17:1) & 0.6 & 9.3 & ND & 0.4 & ND \\
\hline Linoleic acid (C18:2n6c) & ND & ND & ND & 14.6 & 2.7 \\
\hline Linolenic acid (C18:2nc) & ND & ND & ND & 0.1 & ND \\
\hline cis-11,14-Eicosadienoic acid (C20:2) & ND & ND & 7.2 & ND & ND \\
\hline cis-8,11,14-Eicosatrienoic acid (C20:3n3) & 3.7 & 10.3 & ND & 0.2 & ND \\
\hline Arachidonic acid (C20:4n6) & 5.0 & 19.4 & 21.7 & ND & 9.8 \\
\hline cis-13,16-Docosadienoic acid (C22:2) & 5.5 & 16.8 & 16.7 & ND & ND \\
\hline cis-5,8,11,14,17-Eicosapentanoic acid (C20:5n3) & 6.4 & 16.7 & 19.2 & 0.2 & 9.1 \\
\hline cis-4,7,10,13,16,19-Docosahexanoic acid (C22:6n3) & 8.2 & 9.2 & 17.6 & ND & ND \\
\hline Elaidic acid methyl ester(C18:1n9t) & ND & ND & 0.5 & ND & ND \\
\hline Total of trans fat & ND & ND & 0.5 & ND & ND \\
\hline Total of fatty acids: Saturated & 70.6 & 4.9 & 17.1 & 34.6 & 64.1 \\
\hline Total of fatty acids: Monounsaturated & 0.6 & 22.8 & ND & 50.1 & 14.3 \\
\hline Total of fatty acids: Polyunsaturated & 28.8 & 72.4 & 82.4 & 15.1 & 21.6 \\
\hline Total of fatty acids & 99.4 & 100.1 & 100 & 99.8 & 100 \\
\hline
\end{tabular}

ND: Not detected.

Values are means of three independent sets of experiments.

Hence, depending on the neutral lipid content, fatty acid profile and based on the evaluation put forth by Ramos et al. (2009), strain 3589 which demonstrated a good neutral lipid content, a high SFA (34.6\%) and maximal MUFA content $(50.1 \%)$ and comprising of palmitic (C16:0), stearic (C18:0), palmitoleleic (C16:1) and oleic acid (C18:1) and low PUFA content ( $\geq 4$ double bonds, $0.2 \%$ ) was found to be the most suitable for biodiesel production.

\section{Effect of initial glucose concentration on SCO production} Glucose concentration has a significant effect on cell growth and lipid accumulation in batch cultures (Li et al.
2007 Papanikolaou et al. 2009 Zhang et al. 2011). Such preliminary studies are necessary to ascertain the nutrient conditions in order to select a strain with the relevant FAME profile. Glucose is often used as a comparison basis to evaluate the performance of other carbon substrates including wastes. Therefore, we investigated the effect of initial glucose concentration, ranging from 10 to $100 \mathrm{~g} \mathrm{~L}^{-1}$, on biomass, SCO yields and glucose consumed (Glucose cons) by strain 3589. As shown in Figure 3, there was no significant substrate inhibition on cell growth of $Y$. lipolytica 3589 up to $50 \mathrm{~g} \mathrm{~L}^{-1}$ in $48 \mathrm{~h}$. The biomass $\left(\mathrm{X}, \mathrm{g} \mathrm{L}^{-1}\right)$ and lipid yield $\left(\mathrm{L}, \mathrm{g} \mathrm{L}^{-1}\right)$ 
increased to 8.9 and $1.5 \mathrm{~g} \mathrm{~L}^{-1}$ for $50 \mathrm{~g} \mathrm{~L}^{-1}$ glucose (Figure 3). The lipid/dry biomass yield coefficient $\left(\mathrm{Y}_{\mathrm{L} / \mathrm{X}}\right.$, $\left.\mathrm{g} \mathrm{g}^{-1}\right)$ however was maximal at $30 \mathrm{~g} \mathrm{~L}^{-1}\left(0.29 \mathrm{~g} \mathrm{~g}^{-1}\right)$ which decreased to $0.14 \mathrm{gg}^{-1}$ at $100 \mathrm{~g} \mathrm{~L}^{-1}$ glucose. For all the initial glucose concentrations studied, significant concentrations of residual glucose remained at $48 \mathrm{~h}$. (Figure 3).

\section{Biomass and SCO yields of $Y$. lipolytica strains on different wastes}

As expected, an easily utilizable carbon source such as glucose, affected the variation in lipid yields and FAME profiles among the different $Y$. lipolytica strains. It was noted that on an optimal glucose concentration of $30 \mathrm{~g} \mathrm{~L}^{-1}$ in lipid accumulation media, strain 3589 exhibited a FAME profile suitable for biodiesel production. It has also been reported that addition of glucose to wastes enhances lipid production by yeast cells (Xue et al. 2008; Bialy et al. 2011). However, the fermentation cost on high glucose concentrations limits their use for biodiesel production. The use of inexpensive media for lipid fermentation is one of the possible ways to resolve this problem. Therefore, the ability of all Y. lipolytica strains to accumulate lipids on locally available cheap and renewable carbon sources was also evaluated. The results of preliminary studies showing biomass and lipid yields of these strains when cultivated using these wastes $(1 \%$, $\mathrm{w} / \mathrm{v}$ or $\mathrm{v} / \mathrm{v}$ ) after $72 \mathrm{~h}$ are given in Table 2 .

Amongst all the locally available inexpensive wastes studied, the strains exhibited maximal lipid yield coefficients $\left(\mathrm{Y}_{\mathrm{L} / \mathrm{X}}\right)$ on 4 wastes viz., WCO, whey, WMO and fish waste (Table 2). For the other wastes, though a good biomass was achieved, the yields of lipid obtained were relatively lower and hence were not considered further. When grown on WCO, the yields obtained were 0.33 , $0.45,0.33,0.24$ and $0.2 \mathrm{~g} \mathrm{~g}^{-1}$ while on WMO, the yields obtained were: $0.22,0.55,0.17,0.21$ and $0.28 \mathrm{gg}^{-1}$, respectively for strains 3229, 3450, 3472, 3589 and 3590. Cheese whey yielded a $\mathrm{Y}_{\mathrm{L} / \mathrm{X}}$ of $0.13 \mathrm{gg}^{-1}$ for strain 3589 while on fish waste, yields were 0.14 and $0.13 \mathrm{gg}^{-1}$ for strains 3589 and 3590, respectively. Thus strain 3589 was able to accumulate $\mathrm{SCO}$ to varying degrees on all these inexpensive substrates. To date, to the best of our knowledge, no known reports on the substrates chosen in the present study for SCO production by $Y$. lipolytica exist other than WCO (Bialy et al. 2011).

Fatty acid profiles of transesterified SCOs grown on wastes As the fatty acid composition and degree of unsaturation varies with growth substrates, the effect of these four wastes on content and type of fatty acid for all the strains was investigated. As seen in Table 3 strains 3229, 3472 and 3589 exhibited a good lipid content on WCO with respect to SFA, MUFA and PUFA. For the other wastes either the $\mathrm{Y}_{\mathrm{L} / \mathrm{X}}$ yields were low or the content of SFA, MUFA or PUFA were not desirable for biodiesel. The FAME profiles obtained were completely different to those when grown on glucose (Table 4). Though strain 3229 showed good yields, it exhibited very low content of the desirable stearic (C18:0) palmitoleic (C16:1) and oleic (C18:1) acids and hence was not considered as a suitable feedstock for biodiesel. Strain 3472

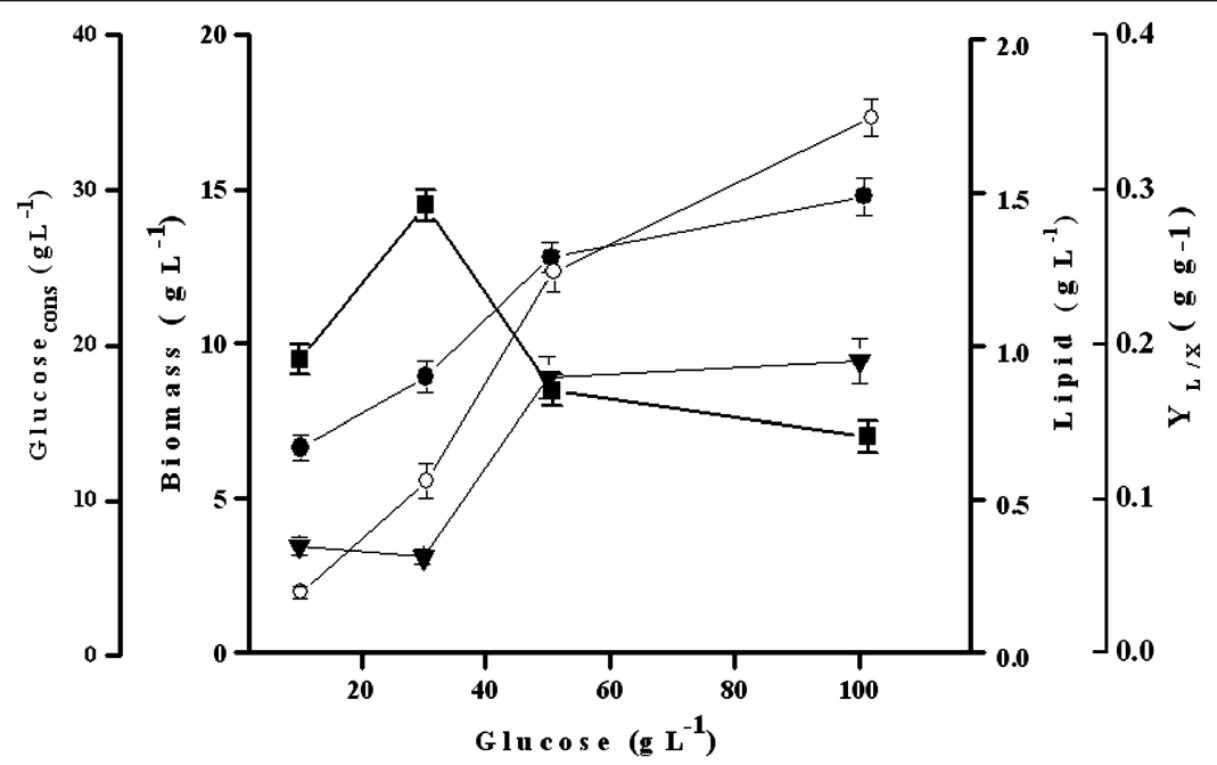

Figure 3 Biomass, lipid yield, glucose consumed and lipid yield coefficients of $Y$. lipolytica NCIM 3589 grown on varying

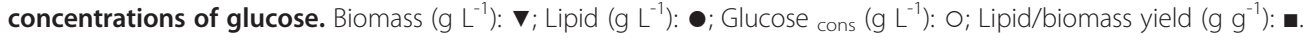


Table 2 Lipid yield coefficient $\left(Y_{L / X}\right)$ of $Y$. lipolytica strains grown on different wastes

\begin{tabular}{|c|c|c|c|c|c|}
\hline Substrate & NCIM 3229 & NCIM 3450 & NCIM 3472 & NCIM 3589 & NCIM 3590 \\
\hline Bagasse & $0.05 \pm 0.02$ & $0.06 \pm 0.02$ & $0.05 \pm 0.02$ & $0.07 \pm 0.02$ & $0.05 \pm 0.01$ \\
\hline Banana peel & $0.05 \pm 0.01$ & $0.04 \pm 0.01$ & $0.06 \pm 0.02$ & $0.09 \pm 0.02$ & $0.05 \pm 0.01$ \\
\hline Cheese whey & $0.03 \pm 0.01$ & $0.05 \pm 0.01$ & $0.03 \pm 0.01$ & $0.13 \pm 0.01$ & $0.05 \pm 0.01$ \\
\hline Chicken feather waste & $0.04 \pm 0 . .02$ & $0.04 \pm 0.02$ & $0.05 \pm 0.02$ & $0.06 \pm 0.03$ & $0.03 \pm 0.01$ \\
\hline Copra meal & $0.04 \pm 0.01$ & $0.03 \pm 0.02$ & $0.02 \pm 0.01$ & $0.04 \pm 0.02$ & $0.03 \pm 0.01$ \\
\hline Fish waste & $0.05 \pm .01$ & $0.06 \pm 0.14$ & $0.11 \pm 0.14$ & $0.14 \pm 0.02$ & $0.13 \pm 0.14$ \\
\hline Grape stalk & $0.05 \pm 0.02$ & $0.04 \pm 0.02$ & $0.05 \pm 0.02$ & $0.06 \pm 0.01$ & $0.05 \pm 0.02$ \\
\hline Groundnut oil cake & $0.04 \pm 0.01$ & $0.03 \pm 0.01$ & $0.02 \pm 0.01$ & $0.04 \pm 0.01$ & $0.03 \pm 0.02$ \\
\hline Groundnut shell waste & $0.02 \pm 0.01$ & $0.04 \pm 0.003$ & $0.01 \pm 0.002$ & $0.03 \pm 0.003$ & $0.03 \pm 0.005$ \\
\hline Orange peel & $0.03 \pm 0.01$ & $0.02 \pm 0.02$ & $0.03 \pm 0.01$ & $0.02 \pm 0.02$ & $0.03 \pm 0.01$ \\
\hline Orange pulp waste & $0.06 \pm 0.01$ & $0.05 \pm 0.02$ & $0.05 \pm 0.02$ & $0.07 \pm 0.02$ & $0.07 \pm 0.06$ \\
\hline Peapod & $0.03 \pm 0.01$ & $0.04 \pm 0.04$ & $0.04 \pm 0.04$ & $0.04 \pm 0.02$ & $0.04 \pm 0.04$ \\
\hline Prawn shell waste & $0.03 \pm 0.01$ & $0.02 \pm 0.01$ & $0.03 \pm 0.01$ & $0.04 \pm 0.02$ & $0.03 \pm 0.01$ \\
\hline Waste cooking oil(WCO) & $0.33 \pm 0.2$ & $0.45 \pm 0.24$ & $0.33 \pm 0.14$ & $0.24 \pm 0.02$ & $0.2 \pm 0.24$ \\
\hline Waste motor oil (WMO) & $0.22 \pm 0.06$ & $0.55 \pm 0.2$ & $0.17 \pm 0.2$ & $0.21 \pm 0.04$ & $0.28 \pm 0.2$ \\
\hline
\end{tabular}

Values are means of three independent sets of experiments.

Differences were considered statistically significant for $p<0.05$.

Table 3 Biomass, lipid content, yield coefficients and fatty acid composition of $Y$. lipolytica strains on wastes

\begin{tabular}{|c|c|c|c|c|c|c|c|}
\hline \multirow{2}{*}{$\begin{array}{l}\text { Y. lipolytica } \\
\text { strain }\end{array}$} & \multirow{2}{*}{$\begin{array}{l}\text { Waste } \\
\text { used }\end{array}$} & \multirow{2}{*}{$\begin{array}{l}X \\
\left(g^{-1}\right)\end{array}$} & \multirow{2}{*}{$\begin{array}{l}\mathrm{L} \\
\left(\mathrm{gL}^{-1}\right)\end{array}$} & \multirow{2}{*}{$\begin{array}{l}Y \mathrm{~L} / \mathrm{X} \\
\left(\mathrm{gg}^{-1}\right)\end{array}$} & \multicolumn{3}{|c|}{ Fatty acids (wt \%) } \\
\hline & & & & & $\overline{T_{\text {SFA }}}$ & $\mathrm{T}_{\text {MUFA }}$ & $\mathrm{T}_{\text {PUFA }}$ \\
\hline \multirow[t]{4}{*}{ NCIM 3229} & Fish & 8.59 & 0.44 & 0.05 & 52.61 & 34.1 & 13.3 \\
\hline & WCO & 7.0 & 2.33 & 0.33 & 56.28 & 31.33 & 11.77 \\
\hline & Whey & 5.91 & 0.23 & 0.03 & 68.4 & 15.6 & 15.5 \\
\hline & WMO & 1.92 & 0.42 & 0.22 & 85.85 & ND & 14.13 \\
\hline \multirow[t]{4}{*}{ NCIM 3450} & Fish & 8.57 & 0.53 & 0.06 & 47.6 & 40.8 & 11.46 \\
\hline & WCO & 5.43 & 2.45 & 0.45 & 79.54 & 14.64 & 4.15 \\
\hline & Whey & 6.91 & 0.29 & 0.05 & 97.97 & 0.45 & 1.54 \\
\hline & WMO & 0.59 & 0.32 & 0.55 & 70.27 & 21.05 & 8.63 \\
\hline \multirow[t]{4}{*}{ NCIM 3472} & Fish & 8.92 & 0.98 & 0.11 & 65.94 & 0.81 & 33.21 \\
\hline & WCO & 7.98 & 2.67 & 0.33 & 28.04 & 71.94 & ND \\
\hline & Whey & 5.7 & 0.2 & 0.04 & 59.6 & 12.63 & 27.74 \\
\hline & WMO & 2.19 & 0.38 & 0.17 & 90.39 & ND & 9.59 \\
\hline \multirow[t]{4}{*}{ NCIM 3589} & Fish & 2.86 & 0.39 & 0.14 & 29.57 & 10.35 & 60.03 \\
\hline & WCO & 5.04 & 1.19 & 0.24 & 56.82 & 32.5 & 11.98 \\
\hline & Whey & 2.6 & 0.33 & 0.13 & 61.98 & 3.69 & 34.3 \\
\hline & WMO & 2.27 & 0.48 & 0.21 & 41.95 & 6.46 & 51.57 \\
\hline \multirow[t]{4}{*}{ NCIM 3590} & Fish & 9.67 & 1.33 & 0.13 & 70.74 & 1.48 & 27.7 \\
\hline & WCO & 7.65 & 2.2 & 0.28 & 77.12 & 1.2 & 20.54 \\
\hline & Whey & 5.49 & 0.28 & 0.05 & 39.68 & 53.22 & 7.05 \\
\hline & WMO & 1.6 & 0.34 & 0.2 & 73.39 & ND & 26.57 \\
\hline
\end{tabular}

$\mathrm{X}$ : Biomass; L: lipid yield; $\mathrm{Y}_{\mathrm{L} / \mathrm{X}}$ : lipid yield coefficient per gram biomass; ND: Not detected.

T SFA: Total of Saturated Fatty Acids; T MUFA: Total of Monounsaturated Fatty Acids; TPUFA: Total of Polyunsaturated Fatty Acids. exhibited good profile when grown on WCO with a high content of MUFA (oleic acid, C18:1), reasonable amount of SFA (lignoceric acid, C24:0) and negligible amounts of PUFA. This was in complete contrast to the profile observed when grown on glucose wherein high contents of PUFAs were obtained. Strain 3589 also exhibited a reasonable profile with a high content of desirable SFA (C8:0 and C16:0) and MUFA (C18:1) with a low PUFA content (C18:2).

\section{Effect of waste cooking oil (WCO) concentration on SCO yields}

The effect of WCO concentrations, ranging from 10 to $100 \mathrm{~g} \mathrm{~L}^{-1}$ on biomass and SCO yields by strains 3472 and 3589 were performed in shake flasks. The WCO was composed of C16:0 (40.5\%), C18:1 (40.9\%) and C18:2 (10.35\%), as determined by GC-FID. As shown in Figure $4 \mathrm{a}$, for strain 3472 , lipid accumulation could be seen by light microscopy and Nile red fluorescence (inset). Maximal biomass $\left(7.9 \mathrm{~g} \mathrm{~L}^{-1}\right)$, lipid yield $\left(3.8 \mathrm{~g} \mathrm{~L}^{-1}\right)$ and $Y_{\mathrm{L} / \mathrm{X}}\left(0.47 \mathrm{gg}^{-1}\right)$ were observed at $30 \mathrm{gL}^{-1}$ in $72 \mathrm{~h}$. Higher WCO concentrations were inhibitory for both growth and lipid yield. For Y. lipolytica 3589, lipid accumulation is shown in Figure 4b inset. No significant substrate inhibition of WCO on cell growth and lipid content up to $100 \mathrm{~g} \mathrm{~L}^{-1}$ in $72 \mathrm{~h}$ was noted (Figure $4 \mathrm{~b}$ ). The cellular biomass as total dry weight $\left(\mathrm{X}_{\text {in }} \mathrm{g} \mathrm{L}^{-1}\right)$ and lipid yield ( $\mathrm{L}^{\left.\text {in } \mathrm{g} \mathrm{L}^{-1}\right)}$ increased up to 10.1 and $4.3 \mathrm{~g} \mathrm{~L}^{-1}$ for $100 \mathrm{~g} \mathrm{~L}^{-1}$ WCO. The lipid/dry biomass yield coefficient $\left(\mathrm{Y}_{\mathrm{L} / \mathrm{X}}, \mathrm{g} \mathrm{g}^{-1}\right)$ was maximal at $100 \mathrm{~g} \mathrm{~L}^{-1}\left(0.43 \mathrm{gg}^{-1}\right)$. Hence the SCOs of both 3472 and 3589 were further investigated for their biodiesel properties. 
Table 4 Fatty acid methyl ester profiles of Y. lipolytica NCIM 3472 and NCIM 3589 on WCO

\begin{tabular}{lll}
\hline \% of fatty acid methyl ester & NCIM 3472 & NCIM 3589 \\
\hline Caprylic acid (C8:0) & ND & 25 \\
Lauric acid (C12:0) & ND & 3.20 \\
Myristic acid (C14:0) & ND & 1.73 \\
Palmitic acid (C16:0) & ND & 21.13 \\
Stearic acid (C18:0) & ND & 3.43 \\
Heneicosanoic acid (C21:0) & ND & 1.79 \\
Behenic acid (C22:0) & 1.54 & ND \\
Lignoceric acid (C24:0) & 26.5 & ND \\
Palmitoleic acid (C16:1) & ND & 0.91 \\
Oleic acid (C18:1n9C) & 71.94 & 21.01 \\
cis-11Eicosanoic acid (C20:1) & ND & 2.00 \\
cis-10-Heptadecanoic acid (C17:1) & ND & 8.01 \\
Linoleic acid (C18:2n6c) & ND & 11.77 \\
Total of fatty acids: Saturated & 28.04 & 56.28 \\
Total of fatty acids: Monounsaturated & 71.94 & 31.93 \\
Total of fatty acids: Polyunsaturated & ND & 11.77 \\
Total of fatty acids & 99.9 & 99.98 \\
\hline
\end{tabular}

ND: Not detected.

The values are the means of three independent determinations.

\section{Biodiesel properties of transesterified SCO (FAME) from strains NCIM 3472 and NCIM 3589}

Direct measurement of fuel properties of biodiesel is quite complex with high cost, error in reproducibility and requiring a considerable amount of fuel sample (Tong et al. 2011). Therefore, prediction models and mathematical equations have been developed to predict biodiesel properties from FAME composition (Azam et al. 2005; Demirbas 1998; Gunstone et al. 2007; Knothe and Steidley 2011; Lapuerta et al. 2010; Pratas et al. 2011; Tong et al. 2011). In the present study, the different physicochemical biodiesel properties viz., density, kinematic viscosity, CN, SN, IV, HHV, TAN, FFA, water content of the sample, copper strip corrosion test were determined for transesterified SCO of the yeast strains 3472 and 3589. The results for the physicochemical properties summarized in Table 5 were performed experimentally as well as determined using models and/or equations based on FAME profiles. While the biodiesel properties for strain 3589 were ascertained when grown on glucose as well as WCO media those for strain 3472 were carried out for the strain grown on WCO. Biodiesel properties of 3472 were not determined when grown on glucose as the strain contained a high amount of PUFA and negligible MUFA (Table 1) which is undesirable for biodiesel.

Among physical properties of biodiesel, strain 3589 with glucose as the carbon source, the density was

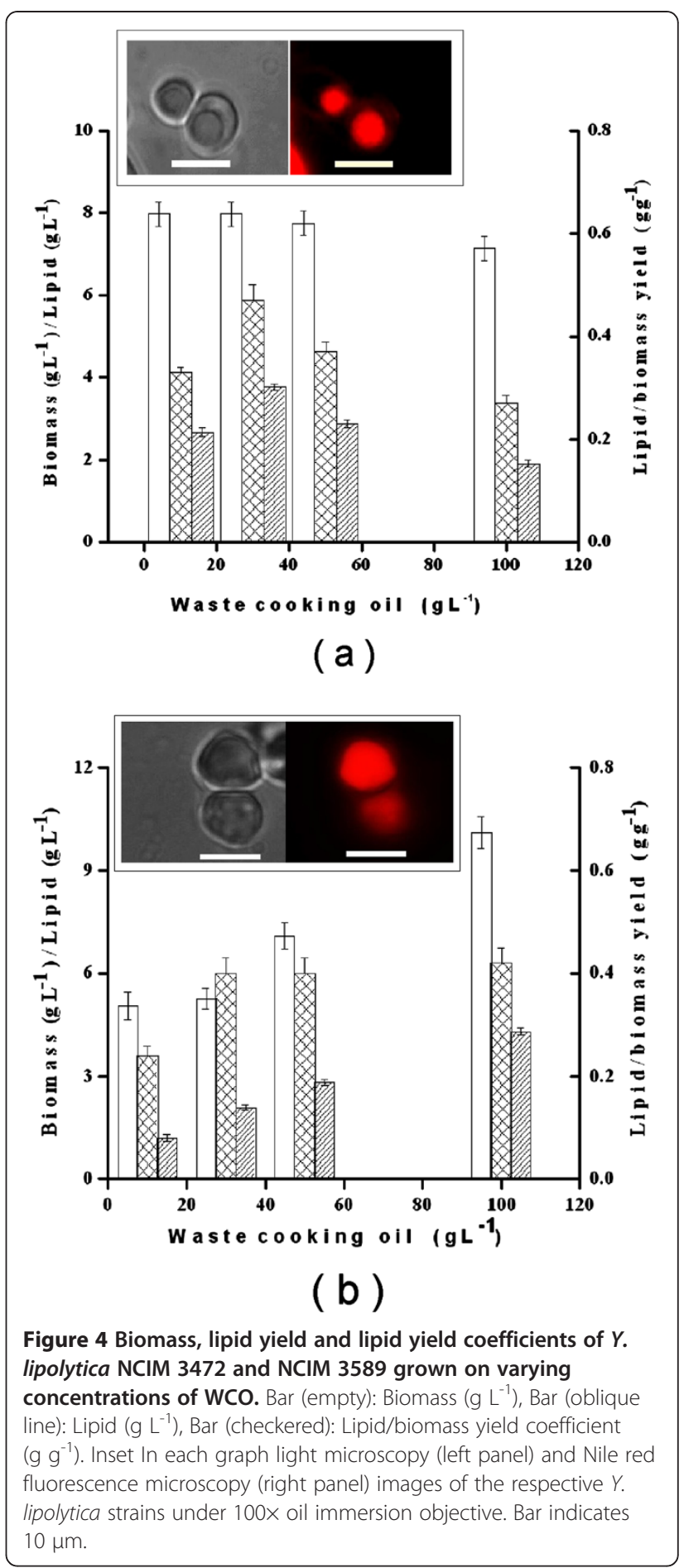

predicted to be $0.87 \mathrm{~g} \mathrm{~cm}^{-3}$ and experimentally determined as $0.81 \mathrm{~g} \mathrm{~cm}^{-3}$ while viscosity was predicted to be $4.44 \mathrm{~mm}^{2} \mathrm{~s}^{-1}$. IV, SN and $\mathrm{HHV}$ are three important chemical properties of biodiesel attributed to the fatty acid profile. The IV is a crude measure of degree of unsaturation of the biodiesel and is often used in 
Table 5 Fuel properties of biodiesel from Y. lipolytica grown on glucose and WCO

\begin{tabular}{|c|c|c|c|c|c|c|}
\hline Property/Test & $\begin{array}{l}\text { Strain NCIM } \\
3589 \text { on glucose }\end{array}$ & $\begin{array}{l}\text { Strain NCIM } \\
3589 \text { on WCO }\end{array}$ & $\begin{array}{l}\text { Strain NCIM } \\
3472 \text { on WCO }\end{array}$ & $\begin{array}{l}\text { US biodiesel } \\
\text { standards } \\
\text { ASTM D6751 }\end{array}$ & $\begin{array}{l}\text { European biodiesel } \\
\text { standards EN14214 }\end{array}$ & $\begin{array}{l}\text { Indian biodiesel } \\
\text { standards } \\
\text { IS15607 }\end{array}$ \\
\hline Visual test & + & + & + & NS & + & NS \\
\hline Density $\left(\mathrm{g} \mathrm{cm}^{-3}\right)^{*}$ & $0.81(0.87)$ & $1.04(0.87)$ & $1.19(0.87)$ & NS & $0.8600-0.900$ & $0.8600-0.900$ \\
\hline Water content (vol \%)* & ND & ND & ND & $0.05 \max$ & $0.25 \max$ & $0.03 \max$ \\
\hline TAN (mg NaOH/g)* & 0.2 & 2.8 & 2.3 & $0.8 \max$ & $0.5 \max$ & $0.5 \max$ \\
\hline FFA $(\%)^{*}$ & 0.1 & 1.4 & 1.15 & NS & NS & NS \\
\hline Cu strip corrosion* & Class 1a & Class 1a & Class 1a & Class 3max & Class 1 max & Class 1max \\
\hline $\mathrm{CN}^{* * *}$ & 56.6 & 50.8 & 59 & $47-65$ & $51 \mathrm{~min}$ & $51 \mathrm{~min}$ \\
\hline $\begin{array}{l}\text { Kinematic viscosity } \\
\left(40^{\circ} \mathrm{C} ; \mathrm{mm}^{2} / \mathrm{s}\right)^{* * *}\end{array}$ & 4.44 & 3.6 & 6.44 & $1.9-6.0$ & $3.5-5.0$ & $3.5-5.0$ \\
\hline $\mathrm{SN}^{*}$ & $190.81(194.48)$ & $256.16(249.4)$ & $168.5(177)$ & NS & NS & NS \\
\hline $\mathrm{IV}^{*}$ & $65.7(70.64)$ & $37.8(47.9)$ & $54.5(61)$ & NS & $120 \max$ & NS \\
\hline$H H V\left(M J k^{-1}\right)^{* * *}$ & 40.39 & 36.77 & 41.25 & NS & NS & NS \\
\hline $\begin{array}{l}\text { Concentration of } \gamma^{\text {-linolenic }} \\
\text { acid (C18:3) (\%)* }\end{array}$ & 0.1 & 0 & 0 & NS & $12 \max$ & NS \\
\hline $\begin{array}{l}\text { FAME having } \geq 4 \text { double } \\
\text { bonds }(\%)^{*}\end{array}$ & $N D$ & ND & ND & NS & $1 \max$ & NS \\
\hline
\end{tabular}

connection with its oxidative stability. The SN indicates the amount of TAG present in total lipid and HHV depends upon both IV and SN. Therefore, in the present study the SN and IV were experimentally determined as well as calculated empirically from fatty ester composition of transesterified total lipids. The experimentally determined (65.7) and the predicted (70.64) IVs were below the EN 14214 specification (120 max) and suggest good oxidative stability of the transesterified oils from strain 3589. The calculated and experimentally determined SNs were found to be 194.48 and 190.81, respectively while $\mathrm{HHV}$ was estimated to be $40.39 \mathrm{MJ} \mathrm{kg}^{-1}$.

For biodiesel, $\mathrm{CN}$ has been found to increase with an increasing weight percentage of saturated and long chain fatty ester. In fact, methyl esters of stearic acid (C18:0), which is of relevance to biodiesel, have been found to possess the highest $\mathrm{CN}(>80)$ (Knothe 2008). In the present study, methyl esters of long chain saturated fatty acids namely stearic acid (C18:0) and palmitic acid (C16:0) were also present in the transesterified yeast oil. The calculated $\mathrm{CN}$ was found to be 56.6 (Table 5), and within the range suggested by the standard norms. The TAN and FFA content as determined experimentally according to EN14214 were estimated to be $0.2 \mathrm{mg} \mathrm{KOH} \mathrm{g}^{-1}$ and $0.1 \%$, in accordance with the biodiesel standards. Other chemical properties of biodiesel evaluated were the concentration of linolenic acid (C18:3) and wt \% of FAMEs having $\geq 4$ double bonds. From the fatty acid profile of the yeast SCO, it can be seen that the concentration of C18:3 (0.1\%) was well below the specified limit of 12 max and fatty esters with $\geq 4$ double bonds were not detected in the transesterified oil (Table 5). These values are in the acceptable range of international biodiesel standard norms suggesting the possible suitability of biodiesel from strain 3589 when grown on glucose.

When grown on WCO as substrate, for strain 3589, the density and TAN were found to be slightly higher at $1.04 \mathrm{~g} \mathrm{~cm}^{-3}$ and $2.8 \mathrm{mg} \mathrm{g}^{-1} \mathrm{NaOH}$, respectively. For strain 3472 , the density $\left(1.19 \mathrm{~g} \mathrm{~cm}^{-3}\right)$, TAN $\left(2.3 \mathrm{mg} \mathrm{g}^{-1}\right.$ $\mathrm{NaOH}), \mathrm{CN}(59)$ and kinematic viscosity $\left(6.44 \mathrm{~mm}^{2} \mathrm{~s}^{-1}\right)$ were found to be much higher than the recommended limits given by the international biodiesel standard norms. All other values for the SCOs from strains 3472 and 3589 were found to lie within the specified limits of the biodiesel standards (Table 5). This is in fact the first report on characterization of biodiesel from any Y. lipolytica strain.

\section{Discussion}

In this study, SCO from strains of a known lipid accumulating model organism $Y$. lipolytica were evaluated to select a lipid yielding strain with higher level of saturated and monounsaturated FAMEs for biodiesel production. All five Y. lipolytica strains tested viz. NCIM 3229, 3450, 34723589 and 3590 were able to accumulate $>20 \%$ of their biomass as cellular lipids.

Glucose concentration has previously been shown to influence the yields of lipid produced, composition of fatty acids as well as their degree of unsaturation in 
oleaginous yeasts Rhodotorula glacialis DBVPG 4785 (Amaretti et al., 2010) Candida sp. 107 (Gill et al. 1997) and Trichsporon fermentans (Zhu et al., 2008). A comparison with other $Y$. lipolytica strains grown on glucose has been tabulated and shown in Table 6. Thus, in this study, the strains produced biomass $\left(3.77-7.42 \mathrm{gL}^{-1}\right)$ and lipid yields, $\left(0.84-1.48 \mathrm{~g} \mathrm{~L}^{-1}\right)$ in $30 \mathrm{~g} \mathrm{~L}^{-1}$ glucose in a short fermentation time of $48 \mathrm{~h}$. While it can be seen that the biomass obtained was comparable to earlier studies, the $Y$. lipolytica strains used in this study produced higher lipid yield coefficients $\left(0.22-0.31 \mathrm{~g} \mathrm{~g}^{-1}\right.$ biomass) to those reported in literature (0.04- $0.14 \mathrm{~g} \mathrm{~g}^{-1}$ biomass) (Table 6). Amongst the lipids, neutral lipids comprising of triacylglycerol (TAG) are the most suitable for direct conversion to biodiesel. In all the five strains the neutral lipid fraction was found to be $88-89 \%$ $(\mathrm{w} / \mathrm{w})$ of the total lipid content. Since biodiesel is derived by trans-esterifying the $\mathrm{SCO}$, the fatty acid composition of the original feedstock determines the quality of biodiesel. Methyl esters from MUFAs viz., palmitoleic (C16:1) and oleic (C18:1) acids are warranted as they are liquid at room temperature and would help in good flow properties. The percentage of unsaturated fatty acids affects the oxidative stability of the final product and quality of biofuel during extended storage (Knothe 2005). A high total PUFA content results in increased viscosity, which again is undesirable for biodiesel. Thus, an ideal biodiesel is made mainly from methyl esters of both SFA and MUFA with low PUFA (Ramos et al. 2009). In this study, amongst all the 5 strains studied, SCO from Y. lipolytica 3589 cultured on $30 \mathrm{~g} \mathrm{~L}^{-1}$ glucose in $48 \mathrm{~h}$ exhibited a good yield coefficient $\left(\mathrm{Y}_{\mathrm{L} / \mathrm{X}}\right)$ $\left(0.29 \mathrm{~g} \mathrm{~g}^{-1}\right)$, biomass $\left(4.16 \mathrm{~g} \mathrm{~L}^{-1}\right)$, high neutral lipid fraction $(89 \% \mathrm{w} / \mathrm{w}$ of total lipid) and a desirable fatty acid profile containing palmitic (24.1\%), stearic $(7.7 \%)$, oleic (38.6\%), palmitoleic (11\%) acids with a lower content of unwanted PUFAs, a composition essential for good quality biodiesel. Strains 3229, 3450, 3472 and 3590 either contained high amounts of PUFA or were low in MUFAs when grown on glucose, making them unsuitable for biodiesel.

The physico-chemical properties of FAMEs of strain 3589 grown on glucose were comparable with the predicted/estimated values reported for biodiesel obtained

Table 6 Comparison of biomass, lipid and fatty acid profiles of various strains of $Y$. lipolytica reported on glucose

\begin{tabular}{|c|c|c|c|c|c|c|c|c|c|c|c|}
\hline \multirow[t]{2}{*}{ S No. } & \multirow{2}{*}{$\begin{array}{l}\text { Strain of } \\
Y . \text { lipolytica }\end{array}$} & \multirow{2}{*}{$\frac{\text { Glucose }}{\left(g^{-1}\right)}$} & \multirow{2}{*}{$\frac{\text { Time }}{\text { (h) }}$} & \multirow{2}{*}{$\frac{X}{\left(g^{-1}\right)}$} & \multirow{2}{*}{$\frac{\mathrm{L}}{\left(\mathrm{gL}^{-1}\right)}$} & \multirow{2}{*}{$\frac{\mathrm{Glu}_{\text {cons }}}{\left(\mathrm{gL}^{-1}\right)}$} & \multirow{2}{*}{$\frac{Y_{\mathrm{L} / \mathrm{X}}}{\left(\mathrm{gg}^{-1}\right)}$} & \multicolumn{3}{|c|}{ Fatty acids (\%) } & \multirow[t]{2}{*}{ References } \\
\hline & & & & & & & & $\mathrm{T}_{\text {SFA }}$ & $\mathrm{T}_{\text {MUFA }}$ & $\overline{T_{\text {PUFA }}}$ & \\
\hline 1 & LGAM S (7) 1 & 28 & 47.5 & 5 & 0.35 & 22.5 & 0.07 & 17.2 & 53.1 & 10.4 & Papanikolaou et al. 2006 \\
\hline 2 & W 29 (ATCC 20460) & 20 & 24 & - & - & - & 0.05 & 11.94 & 30.46 & 47.43 & Beopoulos et al. 2008 \\
\hline \multirow[t]{11}{*}{3} & ACA-YC-5028 & 30 & 98 & 5.5 & - & 28.2 & - & 20.5 & 67.3 & 12.1 & Papanikolaou et al. 2009 \\
\hline & ACA-YC-5029 & & 119 & 4.9 & 0.02 & 23.9 & 0.04 & 17.3 & 75.4 & 7.3 & \\
\hline & ACA-YC-5030 & & 119 & 5.9 & - & 28.9 & - & 16.4 & 78.3 & 5.3 & \\
\hline & ACA-YC-5031 & & 72 & 5.6 & - & 16.9 & - & - & - & - & \\
\hline & ACA-YC-5032 & & 96 & 5.1 & - & 13.5 & - & - & - & - & \\
\hline & ACA-YC-5033 & & 94 & 5.1 & 0.02 & 24.8 & 0.05 & 22.6 & 66.3 & 11.1 & \\
\hline & LFMB 15 & & 95 & 5.2 & - & 13.2 & - & - & - & - & \\
\hline & W 29 & & 142 & 5.8 & 0.06 & 29.2 & 0.06 & 20.4 & 62.3 & 17.3 & \\
\hline & ACA-YC-5029 & 60 & 219 & 3.9 & 0.01 & 50.8 & 0.1 & 17.4 & 72.3 & 9.1 & \\
\hline & ACA-YC-5033 & & 309 & 5.5 & 0.02 & 58.8 & 0.14 & 20.4 & 64.5 & 11.2 & \\
\hline & W 29 & & 315 & 5 & 0.03 & 57.7 & 0.07 & 22.4 & 59.5 & 18.1 & \\
\hline \multirow[t]{3}{*}{4} & W 29 (ATCC 20460) & 35 & 72 & 5.6 & 0.6 & 13.8 & 0.11 & 20.3 & 61.2 & 17 & Sarris et al. 2011 \\
\hline & ACA-YC-5028 & & 72 & - & - & - & - & 25.6 & 50.4 & 24 & \\
\hline & ACA-YC-5033 & & 24 & 4.2 & 0.5 & 5.4 & 0.12 & 23.3 & 62.4 & 12.1 & \\
\hline \multirow[t]{5}{*}{5} & NCIM 3229 & 30 & 96 & 7.42 & 0.83 & 21.11 & 0.22 & 70.6 & 0.6 & 28.8 & Present study \\
\hline & NCIM 3450 & & 24 & 3.23 & 1.01 & 8.36 & 0.31 & 4.9 & 22.8 & 72.4 & \\
\hline & NCIM 3472 & & 48 & 3.58 & 0.89 & 14.02 & 0.25 & 17.1 & 0 & 82.4 & \\
\hline & NCIM 3589 & & 48 & 3.10 & 0.9 & 11.29 & 0.29 & 34.6 & 50.1 & 15.1 & \\
\hline & NCIM 3590 & & 24 & 1.05 & 0.3 & 7.94 & 0.28 & 64.1 & 14.3 & 21.6 & \\
\hline
\end{tabular}

-: Not mentioned; X: Biomass; L: lipid yield; Glu cons: Glucose consumed; $Y_{L / X}$ : lipid yield coefficient per gram biomass; T SFA: Total of Saturated Fatty Acids; T MUFA: Total of Monounsaturated Fatty Acids; TPUFA: Total of Polyunsaturated Fatty Acids. 
from other oleaginous yeasts (Liu and Zhao 2007; Thiru et al. 2011). These values lie within the acceptable range of international biodiesel standard norms and were comparable to vegetable oils (Leung et al. 2010). The free fatty acid (FFA) content was found to be below $0.1 \%$ and FAMEs $\geq 4$ double bonds were not detected, well within the specifications of EN 14214.

$Y$. lipolytica strains, can induce a notable accumulation of reserve lipid when grown on hydrocarbons and fatty substrates. Based on the lipid yield coefficients and FAME profiles, it was seen that the strains 3472 and 3589 could effectively utilize WCO as an inexpensive waste substrate for SCO production. An earlier report by Bialy et al. 2011, has indicated that growth of Y. lipolytica resulted in an increase in total lipid content $\left(0.58 \mathrm{gg}^{-1}\right)$ when grown on frying vegetable oil waste $(0.5 \%, \mathrm{w} / \mathrm{v})$ supplemented with $10 \mathrm{~g} \mathrm{~L}^{-1}$ glucose. Recently an oleaginous yeast $Y$. lipolytica has been shown to produce SCO $\left(0.59 \mathrm{~g} \mathrm{~g}^{-1}\right)$ on sugarcane bagasse hydrolysate medium (Tsigie et al. 2011) while Zygomycetous fungi like Mortierella isabellina have been shown to produce significant quantities of biomass $\left(23.1 \mathrm{~g} \mathrm{~L}^{-1}\right)$ and $\mathrm{Y}_{\mathrm{L} / \mathrm{X}}\left(0.17 \mathrm{gg}^{-1}\right)$ when grown on cheese whey $(100 \%, v / v)$ (Vamvakaki et al. 2010). A previous study has reported a lipid yield coefficient of $0.44-0.54 \mathrm{~g} \mathrm{~g}^{-1}$ on stearin by $Y$. lipolytica ACA-DC-50109 (Papanikolaou and Aggelis 2010) while ATCC 20460 yielded $0.20 \mathrm{~g} \mathrm{~g}^{-1}$ on biodiesel-derived glycerol (Andre et al. 2009). Thus, lipid yield coefficients obtained on WCO in the present study are promising as preliminary data indicates that strain 3589 was able to utilize WCO up to $100 \mathrm{~g} \mathrm{~L}^{-1}$ with $\mathrm{Y}_{\mathrm{L} / \mathrm{X}}$ of $0.43 \mathrm{~g} \mathrm{~g}^{-1}$ while strain 3472 exhibited a $\mathrm{Y}_{\mathrm{L} / \mathrm{X}}$ of $0.47 \mathrm{gg}^{-1}$ on $30 \mathrm{~g} \mathrm{~L}^{-1}$ WCO with higher concentrations being inhibitory.

Both strains exhibited a different FAME profile when grown on WCO as compared to glucose which was reflected in their biodiesel properties. While the TAN values were higher in both the strains than the expected norms, all other properties for strain 3589 seemed to lie within the specified range. For strain 3472, the $\mathrm{CN}$ value, density and kinematic viscosity were also found to be much higher than the expected range. This would most likely be due to the high content $(26.5 \%)$ of the long chain SFA (C24:0) present in the strain. Generally long chain SFAs are not desirable for biodiesel as they are known to increase viscosity thereby affecting flow properties (Knothe 2005). The fuel properties for strain 3589 could be further improved on WCO supplemented with glucose during optimization as reported in the case of $Y$. lipolytica (Bialy et al. 2011) and Trichosporon fermentans (Zhu et al., 2008). This approach may not be possible for strain 3472 as it leads to increased levels of PUFAs when grown on glucose.

Toxic compounds such as aldehydes, semialdehydes, hydrocarbons, alkoxy radicals and acids are generated during the process of reheating WCO which can be inhibitory for microbial growth (Kulkarni and Dalai 2006). Strain 3589 could grow up to $100 \mathrm{~g} \mathrm{~L}^{-1} \mathrm{WCO}$ and accumulate $0.43 \mathrm{~g} \mathrm{~g}^{-1}$ lipid indicating the ability of the strain to tolerate toxic compounds and accumulate lipids at high WCO concentrations. On the other hand, high concentrations of WCO were found to be inhibitory for growth and lipid accumulation in strain 3472 which showed a steady decrease in $\mathrm{Y}_{\mathrm{L} / \mathrm{X}}$ from $10-100 \mathrm{gL}^{-1}$ (0.33-0.27 $\left.\mathrm{gg}^{-1}\right)$, making it unsuitable for further optimization and scale-up studies.

The results obtained in the present study were comparable with those reported for other yeasts. For example, a study on Cryptococcus curvatus for biodiesel production reported a number of fuel properties with similar values including acid value (0.47), density $(0.879 \mathrm{~g}$ $\mathrm{cm}^{-3}$ ) and iodine value (59) (Thiru et al. 2011). Previously, Liu and Zhao (2007) predicted CN values of 59.9 and 63.5 for two oleaginous yeasts, Lipomyces starkeyi and Rhodosporidium toruloides, respectively.

Thus, SCO from the tropical marine yeast $Y$. lipolytica 3589 seems to be a potential feedstock for biodiesel production with the neutral lipid fraction as the major component of their total lipids, the presence of higher quantities of saturated and monounsaturated C16 and C18 fatty acids and lower concentration of long chain PUFAs as the major features. The strain could accumulate lipids upto $0.43 \mathrm{gg}^{-1}$ in the presence of $100 \mathrm{gL}^{-1}$ WCO. The experimentally determined and predicted biodiesel properties based on FAME composition of the yeast SCO of strain 3589 grown on glucose and on WCO are found to lie within the range specified by international biodiesel standard specifications and was therefore identified as a promising strain for further studies. This is the first report on the physico-chemical characterization of biodiesel from any Y. lipolytica strain.

\section{Competing interests}

The authors declare that they have no competing interests.

\section{Authors' contributions}

GK performed the experiments as a part of her doctoral work while CJ carried out the experiments on the wastes. MK participated in the statistical analysis of the data and SSZ helped to draft the manuscript. All this work was carried out under the supervision of ARK who conceived and coordinated the study, designed the experiments and drafted the manuscript. All the authors have read and approved the final manuscript.

\section{Acknowledgement}

The authors thank the Departmental Research Program at Institute of Bioinformatics and Biotechnology (IBB), University of Pune for the financial support provided to carry out this work.

\section{Author details}

'Institute of Bioinformatics and Biotechnology, University of Pune, Ganeshkhind, Pune 411 007, India. ${ }^{2}$ Department of Biotechnology, Manipal Institute of Technology, Manipal 576 104, India.

Received: 29 June 2012 Accepted: 6 July 2012

Published: 19 July 2012 


\section{References}

Amaretti A, Raimondi S, Sala M, Roncaglia L, Lucia M, Leonardi A, Rossi M (2010) Single cell oils of the cold-adapted oleaginous yeast Rhodotorula glacialis DBVPG 4785. Microb Cell Fact 9:73

Andre A, Chatzifragkou A, Diamantopoulou P, Sarris D, Philippoussis A, GaliotouPanayotou M, Komaitis M, Papanikolaou S (2009) Biotechnological conversions of bio-diesel derived crude glycerol by $Y$. lipolytica strains. Eng Life Sci 9(6):468-478

AOCS Method Ce 1-62 (2005) Fatty acid composition by Gas Chromatography. In: Gaithersburg FD (ed) Official methods of analysis of AOAC, 18th edn. Maryland AOAC International

Azam MM, Waris A, Nahar NM (2005) Prospects and potential of fatty acid methyl esters of some non-traditional seed oils for use as biodiesel in India. Biomass Bioenerg 29:293-302

Bankar AV, Kumar AR, Zinjarde SS (2009) Environmental and industrial applications of Y. lipolytica. Appl Microbiol Biotechnol 84:847-865

Beopoulos A, Mrozova Z, Thevenieau F, Le Dall M, Hapala I, Papanikolaou S, Chardot T, Nicaud JM (2008) Control of lipid accumulation in the yeast $Y$. lipolytica. Appl Environ Microbiol 74(24):7779-7789

Beopoulos A, Cescut J, Haddouche R, Uribellerea J, Molina-Jouve C, Nicaud JM (2009) Y. lipolytica as a model for bio-oil production. Prog Lipid Res 48:375-387

Bialy HE, Gomaa OM, Azab KS (2011) Conversion of oil waste to valuable fatty acids using oleaginous yeast. World J Microbiol Biotechnol. doi:10.1007/ s11274-011-0755-x

Demirbas A (1998) Fuel properties and calculation of higher heating values of vegetable oils. Fuel 77:1117-1120

Fickers P, Benetti PH, Wache Y, Marty C, Mauersberger S, Smit MS, Nicaud JM (2005) Hydrophobic substrate utilization by the yeast $Y$. lipolytica, and its potential applications. FEMS Yeast Res 5:527-554

Gill CO, Hall MJ, Ratledge C (1997) Lipid accumulation in an oleaginous yeast (Candida 107) growing on glucose in single-stage continuous culture. Appl Environ Microbiol 33:231-239

Granger LM, Pelot P, Goma G, Pareilleux A (1993) Efficiency of fatty acid synthesis by oleaginous yeasts; Predicition of yield and fatty acid cell content from consumed C/N ratio by a simple method. Biotechnol Bioeng 42:1151-1156

Gunstone FD, Harwood JL, Dijkstra AJ (2007) The Lipid Handbook with CD-ROM, 3rd edn. CRC Press

Kimura K, Yamaoka M, Kamisaka Y (2004) Rapid estimation of lipids in oleaginous fungi and yeasts using Nile red fluorescence. J Microbiol Methods $56: 331-338$

Knothe $\mathrm{G}$ (2005) Dependence of biodiesel fuel properties on the structure of fatty acid alkyl esters. Fuel Process Technol 86:1059-1070

Knothe G (2008) "Designer" Biodiesel: Optimizing fatty ester composition to improve fuel properties. Energ Fuel 22:1358-1364

Knothe G, Steidley KR (2011) Kinematic viscosity of fatty acid methyl esters: Prediction, calculated viscosity contribution of esters with unavailable data, and carbon oxygen equivalents. Fuel. doi:10.1016/j.fuel.2011.06.016

Kosa M, Ragauskas AJ (2011) Lipids from heterotrophic microbes: advances in metabolism research. Trends Biotechnol 29:53-61

Kulkarni MG, Dalai AK (2006) Waste cooking oilan economical source for biodiesel: A review. Ind Eng Chem Res 45(9):2901-2913

Lapuerta M, Rodriguez-Fernandez J, Armas O (2010) Correlation for the estimation of the density of fatty acid esters fuels and its implications. A proposed biodiesel cetane index. Chem Phys Lipids 163:720-727

Latge J, De Bievre C (1980) Lipid composition of Entomophthora obscura Hall \& Dunn. J Gen Microbiol 121:151-158

Leung DYC, Wu X, Leung MKH (2010) A review on biodiesel production using catalyzed transesterification. Appl Energ 87:1083-1095

Li Y, Zhao Z, Bai F (2007) High-density cultivation of oleaginous yeast Rhodosporidium toruloides Y4 in fed-batch culture. Enz Microb Technol 41:312-317

Li Q, Du W, Liu D (2008) Perspectives of microbial oils for biodiesel production. Appl Microbiol Biotechnol 80:749-756

Liu B, Zhao ZK (2007) Biodiesel production by direct methanolysis of oleaginous microbial biomass. J Chem Technol Biotechnol 82:775-780

Meng X, Yang J, Xu X, Zhang L, Nie Q, Xian M (2009) Biodiesel production from oleaginous microorganisms. Renew Energ 34:1-5

Miller GL (1959) Use of dinitrosalicylic acid reagent for determination of reducing sugar. Anal Chem 31:426-428
Minkevich IG, Dedyukhina EG, Chistyakova TI (2010) The effect of lipid content on the elemental energy capacity of yeast biomass. Appl Microbiol Biotechnol 88:799-806

Mlickova K, Roux E, Athenstaedt K, d'Andrea S, Daum G, Chardot T, Nicaud JM (2004) Lipid accumulation, lipid body formation, and acyl coenzyme A oxidases of the yeast Y. lipolytica. Appl Environ Microbiol 70:3918-3924

Official methods of analysis of AOAC (1975) In: Washington HW (ed) Association of Official Analytical Chemists, 12th edn., pp 488-490

Papanikolaou S, Galiotou-Panayotou M, Chevalot I, Komaitis M, Marc I, Aggelis G (2006) Influence of glucose and saturated free-fatty acid mixtures on citric acid and lipid production by Y. lipolytica. Curr Microbiol 52:134-142. doi:10.1007/s00284-005-0223-7

Papanikolaou S, Chatzifragkou A, Fakas S, Galiotou-Panayotou M, Komaitis M, Nicaud JM, Aggelis G (2009) Biosynthesis of lipids and organic acids by $Y$. lipolytica strains cultivated on glucose. Eur J Lipid Sci Technol 111:1221-1232

Papanikolaou S, Aggelis G (2010) Y. lipolytica: A model microorganism used for the production of tailor-made lipids. Eur J Lipid Sci Technol 112:639-654

Papanikolaou S, Dimou A, Fakas S, Diamantopoulou P, Philippoussis A, GaliotouPanayotou M, Aggelis G (2010) Biotechnological conversion of waste cooking olive oil into lipid-rich biomass using Aspergillus and Penicillium strains. J Appl Microbiol 110:1138-1150

Papanikolaou S, Aggelis G (2011) Lipids of oleaginous yeasts. Part II: Technology and potential applications. Eur J Lipid Sci Technol 113:1052-1073

Pratas MJ, Freitas SVD, Oliveira MB, Monteiro SC, Lima AS, Coutinho JAP (2011) Biodiesel density: Experimental measurements and prediction models. Energ Fuel 25:2333-2340

Ramos MJ, Fernández CM, Casas A, Rodríguez L, Perez Á (2009) Influence of fatty acid composition of raw materials on biodiesel properties. Bioresour Technol 100:261-268

Ratledge C, Wynn JP (2002) The biochemistry and biotechnology of lipid accumulation in oleaginous microorganisms. Adv Appl Microbiol 51:1-51

Sarris D, Galiotou-Panayotou M, Koutinas A, Komaitis M, Papanikolaou S (2011) Citric acid, biomass and cellular lipid production by Y. lipolytica strains cultivated on olive mill wastewater-based media. J Chem Technol Biotechnol 86:1439-1448

Schneiter R, Daum G (2006) Extraction of yeast lipids. In: Xiao W (ed) Methods in molecular biology, vol 313, 2nd edn, Yeast Protocols. Humana Press Inc, pp $41-45$

Subramaniam R, Dufreche S, Zappi M, Bajpai R (2010) Microbial lipids from renewable resources: production and characterization. J Ind Microbiol Biotechnol 37:1271-1287

Suutari M, Priha P, Laakso S (1993) Temperature shifts in regulation of lipids accumlated by Lipomyces starkeyi. J Am Oil Chem Soc 70:891-894

Thiru M, Sankh S, Rangaswamy V (2011) Process for biodiesel production from Cryptococcus curvatus. Bioresour Technol 102:10436-10440. doi:10.1016/j. biortech.2011.08.102

Tong D, Hu C, Jiang K, Li Y (2011) Cetane number prediction of biodiesel from the composition of the fatty acid methyl esters. J Am Oil Chem Soc 88:415-423

Tsigie YA, Wang C-Y, Truong C-T, Ju Y-H (2011) Lipid production from Y. lipolytica Polg grown in sugarcane bagasse hydrolysate. Biores Technol 648(102):9216-9222

Vamvakaki A-N, Kandarakis I, Kaminarides S, Komaitis M, Papanikolaou S (2010) Cheese whey as a renewable substrate for microbial lipid and biomass production by Zygomycetes. Eng Life Sci 10(4):348-360

Venkata Subhash G, Venkata Mohan S (2011) Biodiesel production from isolated oleaginous fungi Aspergillus sp. using corncob waste liquor as a substrate. Bioresour Technol 102:9286-9290

Xue F, Miao J, Zhang X, Luo H, Tan T (2008) Studies on lipid production by Rhodotorula glutinis fermentation using monosodium glutamate wastewater as culture medium. Bioresour Technol 99:5923-5927

Zhang J, Fang X, Zhu X-L, Li Y, Xu H-P, Zhao B-F, Chen L, Zhang X-D (2011) Microbial lipid production by the oleaginous yeast Cryptococcus curvatus $\mathrm{O} 3$ grown in fed batch culture. Biomass Bioenerg 35:1906-1911

Zhu L, Zong M, Wu H (2008) Efficient lipid production with Trichosporon fermentans and its use for biodiesel preparation. Biores Technol 99:7881-7885

doi:10.1186/2191-0855-2-36

Cite this article as: Katre et al.: Evaluation of single cell oil (SCO) from a tropical marine yeast Yarrowia lipolytica NCIM 3589 as a potential feedstock for biodiesel. AMB Express 2012 2:36. 